\title{
RESEARCH ORIENTED REMOTE SENSING IMAGE PROCESSING SOFTWARE DESIGN IN PRACTICAL COURSES FOR SENIOR UNDERGRADUATES
}

\author{
Haopeng Zhang, Danpei Zhao, Fengying Xie, Zhiguo Jiang \\ Department of Aerospace Information Engineering, School of Astronautics, \\ Beihang University, 102206 Beijing, China - zhanghaopeng@ buaa.edu.cn
}

Commission V, WG V/1

KEY WORDS: Practical Courses, Academic Research, Software Design, Remote Sensing, Image Processing.

\begin{abstract}
:
Remote sensing is not only the teaching content of the majors of surveying and mapping, but also the teaching content of many other engineering majors in China, such as Detection, Guidance and Control Technology (DGCT), Aerocraft Control and Information Engineering (ACIE), etc. In this paper, we put forward the special teaching task of remote sensing image processing software design to the practical courses, named Specialty Course Design and Specialty Comprehensive Experiments, for senior engineering undergraduate students in their last academic year. In this research oriented task, students are required to design, code and implement a remote sensing image processing software under the specified software programming conditions, and carry out detailed software testing, so as to meet several application functions with research objectives. According to the collation and summary of five rounds of teaching practice of such research oriented remote sensing image processing software design tasks in practical courses, we find that it can not only cultivate the ability of students to comprehensively use the knowledge they have learned, but also enable them to better analyze the actual application needs and acquire the technology and ability closer to the actual work needs.
\end{abstract}

\section{INTRODUCTION}

In most universities in China, there are two required practical courses, named Specialty Course Design and Specialty Comprehensive Experiments for senior engineering undergraduate students in their last academic year (Zhou et al., 2014, Wang and $\mathrm{Fu}, 2018$, Zhang et al., 2020, Zheng and Ma, 2020). The purpose of such practical courses is to enable students to master the basic ability of handling engineering problems in their major through a total of 6 weeks of centralized design and experiment (3 weeks for Specialty Course Design and 3 weeks for Specialty Comprehensive Experiments). In the cultivation of engineering students in China, Specialty Course Design and Specialty Comprehensive Experiments are important training links to help students summarize the theoretical knowledge of their major, analyze practical engineering problems and improve their practical ability.

Since the rise of remote sensing technology in 1960s, remote sensing is not only the teaching content of the majors of surveying and mapping, but also the teaching content of many other engineering majors. In 2016, China set up a new undergraduate major Aerocraft Control and Information Engineering (ACIE) in the aerospace major class, so as to cultivate information processing talents for the aerospace field and adapt to the rapid change of information technology to the traditional industry. Beihang University, which takes aerospace as its advantage, began to recruit undergraduates majoring in ACIE from 2017, and the Department of Aerospace Information Engineering of School of Astronautics is responsible for teaching and personnel training. On the basis of the teaching experience for the major of Detection, Guidance and Control Technology (DGCT, a related major in which the students learn remote sensing as well), in the practical courses of ACIE, we put forward the special teaching task of remote sensing image processing software

\footnotetext{
* Corresponding author
}

design. In this research oriented task, students are required to design, code and implement a remote sensing image processing software under the specified software programming conditions, and carry out detailed software testing, so as to meet several application functions with research objectives. As is known to all, with the development of sensor technology, aerospace vehicle technology and information technology, people can get a lot of high-quality remote sensing data more and more easily. However, due to the limited professional manpower, most of the remote sensing data cannot be accurately read manually. So it is necessary to use computer software to process remote sensing image automatically and intelligently. In addition, image processing is also a key technology widely used in remote sensing for a long time (Nagy, 1972, Meer et al., 2011, Liu et al., 2012). Thus it is suitable to set a task of remote sensing image processing software design and coding in practical courses for senior undergraduates.

Since 2015, we have carried out research oriented remote sensing image processing software design tasks in practical courses. After five rounds of teaching practice, we have gradually understood the talent training performance of the task of remote sensing image processing software design. This paper is the collation and summary of this effect.

The rest of this paper is organized as following. We analyze the problems in previous practical courses in Section 2, and introduce the details of our five-year teaching practice of research oriented remote sensing image processing software design tasks in practical courses performed in Beihang University for 171 senior undergraduate students in Section 3. Section 4 concludes the performance of our teaching practice. 


\section{PROBLEMS AND SOLUTION}

In practical courses of Specialty Course Design and Specialty Comprehensive Experiments before 2015, there are four main problems.

Firstly, these two courses are not related and their contents are not connected either. The two practical courses of Specialty Course Design and Specialty Comprehensive Experiments are independent of each other. There is no essential connection and inheritance relationship between them. They lack systematic design and comprehensive analysis content, and have no obvious improvement compared with the experiments within theoretical courses.

Secondly, students lack the ability to analyze problems systematically. The professional knowledge learned by the undergraduates is scattered. Their problem-solving is passive. They lack practices of systematic and macroscopic observation and thinking ability, and thus their analysis of problems is not comprehensive, macroscopic and systematic.

Thirdly, the ability of students to cooperate with each other is poor. Students usually complete the course learning tasks individually. They lack the training of team works, and have little initiative to carry out team work with others.

Lastly, the students' ability of expression is poor. There is no requirement of oral representation in course assignment or experimental report. Students lack the opportunity to represent their work orally to others, so their expression ability is generally poor.

To solve these problems, we reform the courses of Specialty Course Design and Specialty Comprehensive Experiments using a single task of remote sensing image processing software design. In the course of Specialty Course Design, students are required to design a software to achieve some functions for remote sensing image processing. While in the course of Specialty Comprehensive Experiments, students are required to implement the software they designed by coding themselves, and carry out detailed software testing to validate the performance of their software. It should be noticed that, students are asked to finish such task by teams, not individually. At the end of the courses, each team is also asked to orally represent their work to the teacher and other teams.

\section{TEACHING PRACTICE}

Five rounds of teaching practice of the aforementioned research oriented remote sensing image processing software design task in practical courses of Specialty Course Design and Specialty Comprehensive Experiments have been carried out since 2015. This section will describe some details of our practice.

\subsection{Team Members}

The research oriented software design task is required to be completed by students in a group with 3-7 members. Because the duration of the practical courses is only 6 weeks, more software functions can be completed in a short time by team work, making the software more practical. At the same time, it can also train students' team work ability.

\subsection{Task Update}

For different students every year, the specific software design requirements are not fixed. The functional requirements will change based on research frontier and works finished in the previous year. This not only keeps the inheritance, but also contains new challenges. For example, in the first round of the design task in 2015, we required the students to achieve reading, visualization, saving, clipping, scaling and filtering of remote sensing images in the software. While in 2019, we asked the team to detect fires in remote sensing images. Table 1 summarizes the required functions of the remote sensing image processing software in academic years 2015 to 2019. It can be seen that the task is keeping updated year by year. Figure 1 shows the software achieved by the students from 2015 to 2019 .

\begin{tabular}{c|l}
\hline Years & Functional requirements \\
\hline 2015 & $\begin{array}{l}\text { read, write, and display remote sening images } \\
\text { image resampling } \\
\text { image clip } \\
\text { image enhancement }\end{array}$ \\
\hline 2016 & $\begin{array}{l}\text { read, write, and display remote sening images } \\
\text { image resampling } \\
\text { image clip } \\
\text { image enhancement } \\
\text { image segmentation } \\
\text { edge detection }\end{array}$ \\
\hline \multirow{2}{*}{2017} & $\begin{array}{l}\text { read, write, and display remote sening images } \\
\text { image clip } \\
\text { image enhancement } \\
\text { image segmentation } \\
\text { edge detection } \\
\text { change detection }\end{array}$ \\
\hline $\begin{array}{l}\text { read, write, and display remote sening images } \\
\text { image resampling } \\
\text { image clip } \\
\text { image enhancement } \\
\text { singe image super-resolution } \\
\text { image quality assessment }\end{array}$ \\
$\begin{array}{l}\text { read, write, and display remote sening images } \\
\text { image resampling } \\
\text { image clip } \\
\text { image enhancement } \\
\text { fire detection in infrared remote sensing images }\end{array}$ \\
\hline
\end{tabular}

Table 1. Required functions of the remote sensing image processing software. Bold text indicates updated contents.

\subsection{Poster Presentation}

We refer to the poster form of the academic conferences, and organize students to show their software design results every year for mutual exchange and reference. By taking the poster presentations, the students can exercise their expression ability and experience academic exchange activities in advance. Figure 2 shows the poster presentation in 2018, including a poster sample, the scene of conference hall, and the picture of discussion between teachers and students.

\section{CONCLUSIONS}

The teaching practice shows that setting up the research oriented task of remote sensing image processing software design in practical courses can not only cultivate the ability of students to comprehensively use the knowledge they have learned, but also enable them to better analyze the actual application needs and acquire the technology and ability closer to the actual work needs. Such research oriented tasks have received positive feedbacks by the in-class students. 

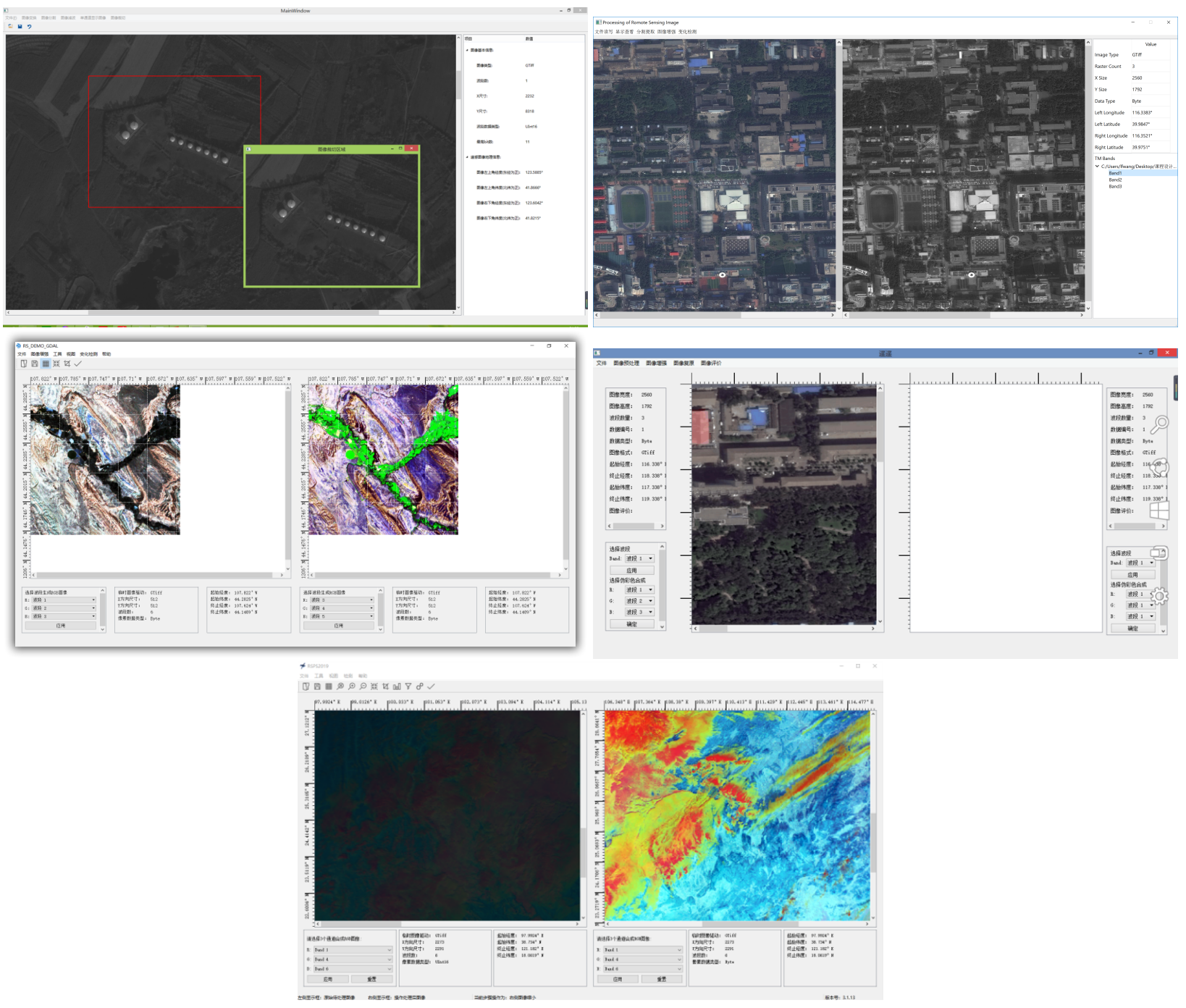

Figure 1. Software achieved by the students from 2015 to 2019.

\section{ACKNOWLEDGEMENTS}

This work was supported by the Teaching Reform Project of Beihang University (Grant No. 4305023) named "Research on innovation and practice ability training system for undergraduates majoring in Aerocraft Control and Information Engineering".

\section{REFERENCES}

Liu, C., Han, R., Lu, X., 2012. Teaching of Digital Image Processing Course in Remote Sensing Science and Technology Specialty. Geospatial Information, 10(3), 180-182.

Meer, F., Abrams, M., Curran, P., Dekker, A., Jong, S. D., 2011. Remote Sensing and Digital Image Processing. International Archives of the Photogrammetry, Remote Sensing and Spatial Information Sciences, Vol. XXXIV, Part 6, CVI, 211-236.

Nagy, G., 1972. Digital image-processing activities in remote sensing for earth resources. Proceedings of the IEEE, 60(10), $1177-1200$

Wang, L., Fu, L., 2018. CDIO-based automation and electrical engineering course design and comprehensive experimental teaching reform. Research in Teaching, 41(03), 88-93.
Zhang, Q., Wang, H., Wang, H., Wang, M., Pan, J., 2020. Comprehensive course design of computer major from the perspective of professional certification. Computer Education, 2020(8), 152-156.

Zheng, H., Ma, X., 2020. Teaching reform and practice of industrial engineering course design. China Electric Power Education, 2020(03), 70-72.

Zhou, Q., Zhang, B., Zhang, D., Zhao, Y., Feng, Y., 2014. Design and practice on special comprehensive experimental courses guided by project-driven. Experimental Technology and Management, 31(03), 183-185. 
The International Archives of the Photogrammetry, Remote Sensing and Spatial Information Sciences, Volume XLIII-B5-2021 XXIV ISPRS Congress (2021 edition)
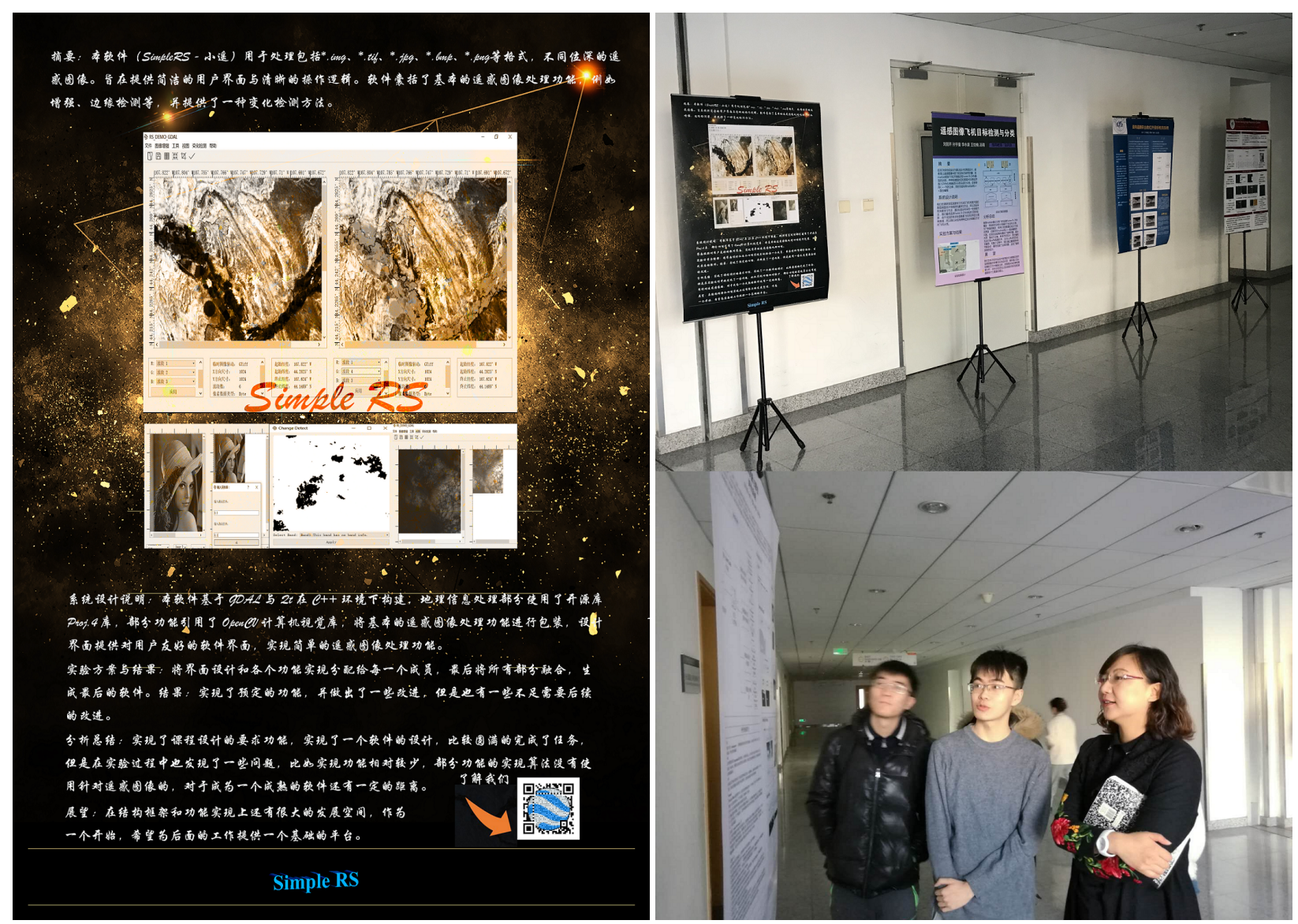

Figure 2. Poster presentation in 2018. 